\title{
Rapid Synthesis of DNA Deletion Constructs for mRNA Quantitation: Analysis of Astrocyte mRNAs
}

\author{
Elena Galea and Douglas L. Feinstein \\ Division of Neurobiology, Department of Neuroscience and Neurology, Cornell University Medical College, \\ New York, New York 10021
}

\begin{abstract}
A rapid method for the synthesis of DNA fragments for competitive PCR analysis is described. This procedure takes advantage of the fact that if PCR is carried out with a mixture of re-ligated restriction digestion fragments, only those fragments containing binding sites for both PCR primers will be amplified. Following electrophoresis of the amplified mixture, the DNA fragment of desired size can be excised from an agarose gel, reamplified, and used for subsequent competitive PCR. We have used this procedure to synthesize deletion constructs for the rat glial fibrillary acidic protein (GFAP) gene, and have used competitive PCR to determine the levels of this mRNA in primary cultures of rat brain astrocytes.
\end{abstract}

$\mathbf{R}$ ecently, a number of PCR-based methods that allow the rapid and sensitive quantitation of cellular mRNA levels have been described. In the technique of competitive PCR, ${ }^{(1-5)}$ an internal standard is coamplified with the sample, and at the end the relative amount of each product is determined. Since the efficiency of amplification of the standard is identical to that of the sample template, problems associated with the variability between different $P C R$ reactions are circumvented. A number of techniques have been developed to generate internal standards, including those that produce standards having altered restriction sites, ${ }^{(1,3,4)}$ standards of different lengths, ${ }^{(1,2,5)}$ and standards derived from other genes that fortuitously use the same primers but whose internal sequence remains unknown. ${ }^{(2)}$ Although each of these techniques provides certain advantages, fragments differing by minimal sequence information will provide standards with the amplification properties closest to those of the actual sample being measured. To achieve this, we have developed a rapid method to generate deletion constructs, and applied it to the quantitation of an mRNA specifically expressed in glial cells of the mammalian central nervous system.

\section{METHODS}

\section{Synthesis of Deletion Construct}

Synthetic oligonucleotides were prepared on a Milligen-Biosearch Cyclone DNA synthesizer, corresponding to bases 13-32 (primer 1, 5'-GAAGCAGGGCAAGATGGAGC-3') and complementary to bases 276-296 (primer 2, 5'-GCTGTTC-
CAGGAAGCGGACCT- $3^{\prime}$ ) of the rat glial fibrillary acidic protein (GFAP) mRNA sequence. ${ }^{(7)}$ Primers 1 and 2 were used to amplify the corresponding region of clone rGFA15, a 5.7-kb rat cDNA clone that contains the entire rat GFAP sequence (2804 bp). ${ }^{(7)}$ An aliquot of the PCR reaction mixture was used without further purification for restriction enzyme digestion. A $2-\mu l$ aliquot (approximately $200 \mathrm{ng}$ ) of the $50-\mu \mathrm{l}$ mixture was incubated in a total volume of $20 \mu \mathrm{l}$ with restriction enzyme HaeIII (5 units) for 15 min at $37^{\circ} \mathrm{C}$. The sample was then heated at $68^{\circ} \mathrm{C}$ for $5 \mathrm{~min}$ to inactivate the restriction enzyme. An aliquot ( $5 \mu \mathrm{l}$, containing $\sim 50 \mathrm{ng}$ ) was self-ligated for $15 \mathrm{~min}$ at $37^{\circ} \mathrm{C}$ with $\mathrm{T} 4$ DNA ligase ( 3 units) in a final volume of $20 \mu \mathrm{l}$. An aliquot $(5 \mu \mathrm{l}$, $\sim 12.5 \mathrm{ng}$ ) of the religated material was then used for 30 cycles of PCR amplification, and the products were separated by electrophoresis through a $3 \%$ NuSieve low-melting-point agarose gel. A major product of 155 bp was excised from the gel, and 2- or 5- $\mu$ l aliquots of the melted agarose were amplified as above. The products were then purified by affinity chromatography (Qiagen) and stored in aliquots at $-20^{\circ} \mathrm{C}$.

\section{Synthesis of CDNA}

An aliquot of total cytoplasmic RNA (10 $\mu \mathrm{g}$ ) was mixed with $400 \mathrm{ng}$ of primer 2 in a total volume of $11 \mu \mathrm{l}$, heated at $65^{\circ} \mathrm{C}$ for $2 \mathrm{~min}$, and then placed on ice. Synthesis of cDNA was carried out in a final volume of $20 \mu \mathrm{l}$ in the presence of 40 $\mathrm{mm} \mathrm{KCl}, 2.5 \mathrm{~mm}$ each dNTP, and 2 units of Superscript RNase $\mathrm{H}^{-}$reverse transcriptase (Pharmacia), at $42^{\circ} \mathrm{C}$ for $1 \mathrm{hr}$. 
The reaction was terminated by heating at $95^{\circ} \mathrm{C}$ for $2 \mathrm{~min}$, and an aliquot was used directly for PCR analysis.

\section{PCR Conditions}

PCR amplifications were carried out in a Perkin-Elmer Cetus Model 900 temperature cycler. The standard reaction mixture contained the template DNA $(2-5 \mu \mathrm{l}$ of low-melting-point agarose, $1 \mu$ l of the total $20-\mu 1$ cDNA product reaction mixture, or 0.5-5 ng of plasmid rGFA15), 400 ng of each primer, $200 \mu \mathrm{M}$ each dNTP, 50 $\mathrm{mm} \mathrm{KCl}, 10 \mathrm{~mm}$ Tris- $\mathrm{Cl}, \mathrm{pH} 8.8$, at $25^{\circ} \mathrm{C}$, $1.5 \mathrm{mM} \mathrm{MgCl}_{2}, 0.5 \mathrm{~mm}$ DTT, and $0.1 \%$ Triton X-100 in a final volume of $50 \mu \mathrm{l}$. For competitive PCR, various amounts of the deletion construct were added along with the cDNA or plasmid sample. The reaction was initiated by the addition of 0.5 units of Taq DNA polymerase (Promega) in a volume of $5 \mu l$ to the Eppendorf tube during the denaturation cycle. The parameters of amplification were: denaturation at $93^{\circ} \mathrm{C}$ for $1 \mathrm{~min}$, annealing at $64^{\circ} \mathrm{C}$ for $1 \mathrm{~min}$, and synthesis at $72^{\circ} \mathrm{C}$ for $1 \mathrm{~min}$. Unless specified otherwise, 25 cycles of amplification were carried out for competitive PCR.

\section{Quantitation}

Following amplification of template samples in the presence of known amounts of deletion construct, the PCR products were separated by electrophoresis through a $2 \%$ agarose gel containing $1 \mu \mathrm{g} / \mathrm{ml}$ of ethidium bromide, and the gel was photographed with Polaroid Type 665 film. The relative optical densities of the sample and the deletion construct bands were determined by laser densitometry of the film negative on a LKB Ultroscan XL densitometer. Different volumes of the reaction mixtures were loaded onto gels to obtain images where the intensity of the bands were within the linear range of the densitometer, as determined by previous calibrations.

For calculations, the log of sample/ construct band intensities was plotted versus log of added construct. The point at which the band intensities are the same $(Y$ value $=0)$ represents the point at which the two PCR products are present at equal masses; thus, the amount of sample initially present (in picograms) was equal to the known amount of added construct (in picograms).

\section{Other procedures}

Primary cultures of rat brain astrocytes were prepared from neonatal cerebral cortex as described. ${ }^{(6)}$ Cells were used after 2 weeks, at which point more than $95 \%$ of the cells stained positively for the astrocyte-specific marker GFAP. Total cytoplasmic RNA was isolated from astrocyte cultures using the NP-40 lysis procedure, ${ }^{(8)}$ as described previously. ${ }^{(6)}$

\section{RESULTS}

The procedure we have used to prepare deletion constructs is outlined in Figure 1, using the rat GFAP gene sequence as a model system. Amplification of the template DNA (plasmid rGFA15) using primers 1 and 2 leads to the production of a single PCR product of 284 bp (Fig. 2A, lane A). This portion of the rat GFAP sequence contains three sites for cleavage by the restriction enzyme HaelII yielding

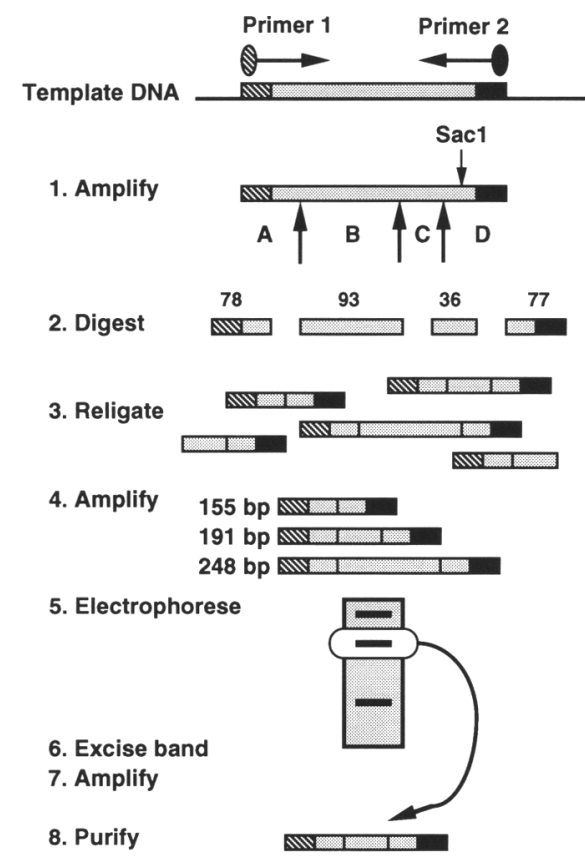

FIGURE 1 Procedure for synthesis of DNA deletion constructs. The process is illustrated using the rat GFAP template as an example. The individual steps are described in the text. A-D refer to HaeIII restriction digest products. Numbers refer to the sizes in base pairs of the HaeIII digestion products and religated fragments. The unique Sacl restriction site at +242 in this portion of the GFAP sequence is shown.
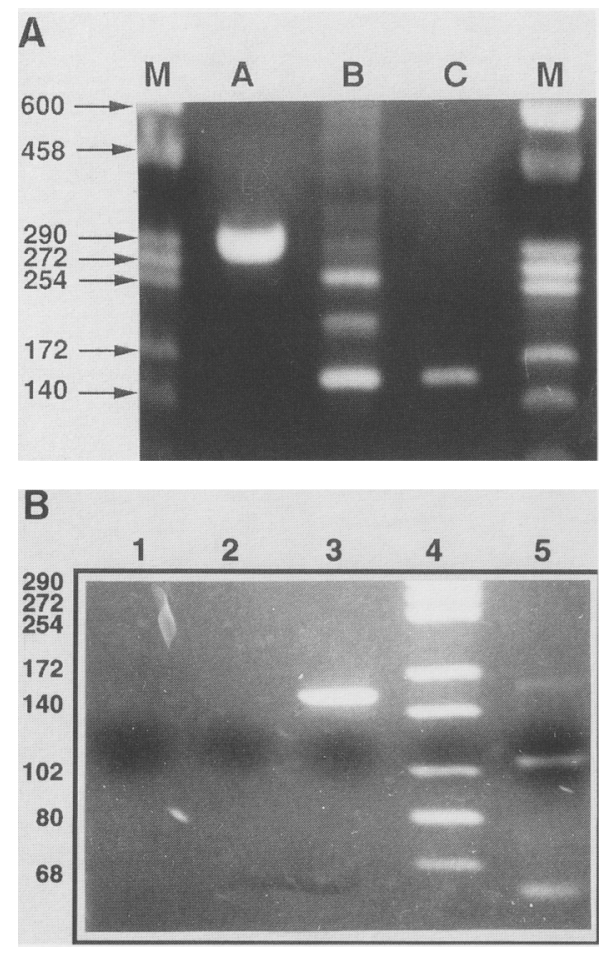

FIGURE 2 Synthesis of GFAP deletion construct. (A) Samples from the main steps of the construction pathway: (lane $M$ ) DNA size markers; (lane $A$ ) 284-bp PCR product; (lane $B$ ) amplified self-ligated fragments; (lane $C$ ) amplified 155-bp fragment. (B) Verification of product identity. The 155 -bp product was amplified in the presence of primer 1 alone (lane 1); primer 2 alone (lane 2); primers 1 and 2 (lane 3); DNA markers (lane 4); products of the 155-bp construct digested with Sacl (lane 5 ). Note that this lane shows a partial digest in which a low amount of the undigested 155-bp product can still be seen.

fragments of $78 \mathrm{bp}(\mathrm{A}), 93 \mathrm{bp}$ (B), $36 \mathrm{bp}$ (C), and $77 \mathrm{bp}(\mathrm{D})$. To obtain deletion constructs that would be easily separable from the full-length 284-bp product, we chose to delete one or both of the two central HaeIII fragments. To accomplish this, we reasoned that following religation of the products of HaeIII digestion, only those products containing fragments $A$ and $D$ would be amplified by PCR using primers 1 and 2 . The deletion fragment of desired size could then be purified from others by electrophoresis through a low-melting-point agarose gel.

An aliquot of the PCR reaction mixture containing the 284-bp product (Fig. $2 \mathrm{~A}$, lane A) was used without purification for HaeIII digestion, followed by a brief ligation step. PCR amplification of the self-ligated HaeIII digest resulted in the production of three major products, 
whose sizes corresponded to religation products $A+D(155 \mathrm{bp}), A+C+D(191$ bp), and $A+B+D$ (248 bp) (Fig. 2A, lane $B)$, as well as numerous other minor products of higher molecular weights. We confirmed that the 155-bp product was due to $A+D$ ligation, and not $A+A$ (156 bp) or D+D (154 bp) because (1) amplification with either primer 1 or primer 2 alone did not result in product formation (Fig. 2B, lanes 1 and 2), and (2) the products of restriction enzyme digestion with SacI, which cuts at +242 , were those expected of the A + B product, e.g., 103 and 52 bp (Fig. 2B, lane 5). The area of the gel containing the 155-bp product was excised, and 5- $\mu$ l aliquots of the sample in melted agarose were amplified to obtain large amounts of the specific product. The products of $10 \mathrm{in}$ dividual 50- $\mu$ l PCR reactions were combined and purified by affinity chromatography over a Qiagen Tip-100. Following ethanol precipitation, we recovered approximately $25 \mu \mathrm{g}$ of the 155 bp deletion construct (Fig. 2A, lane C).

The ability of the 155-bp construct to compete for primers with full-length GFAP CDNA was tested by adding increasing amounts of the construct to a constant amount of plasmid rGFA15, and carrying out 25 cycles of PCR (Fig. $3)$. A reversal of relative band intensities occurred between 10 and $50 \mathrm{pg}$ of added construct, consistent with the amount of 284-bp fragment present in the added plasmid. (Because the 284-bp fragment

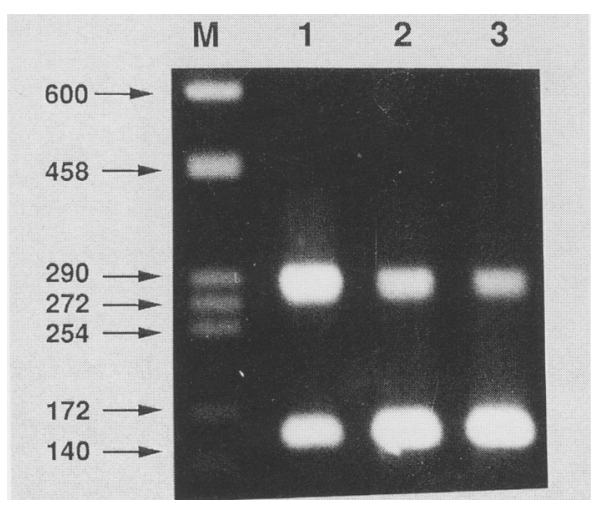

FIGURE 3 Competition between GFA 155-bp construct and plasmid rGFA15. Different amounts of the 155-bp construct were coamplified with approximately $0.5 \mathrm{ng}$ of plasmid rGFA15, of which $25 \mathrm{pg}(5 \%)$ corresponds to the 284-bp fragment being amplified. The amounts of 155 -bp construct are $10 \mathrm{pg}$ (lane 1); $50 \mathrm{pg}$ (lane 2); $100 \mathrm{pg}$ (lane 3 ). DNA size markers (lane $M$ ) are indicated. constitutes $5 \%$ of the entire plasmid weight, the amount of 284-bp fragment added in $0.5 \mathrm{ng}$ of plasmid amounted to $25 \mathrm{pg}$.) As the amount of added construct was increased, the relative intensity of the 284-bp product decreased, reflecting the competition occurring between the two templates.

This construct was used for determining GFAP mRNA levels in samples of RNA isolated from primary cultures of rat brain astrocytes (Fig. 4 inset). Visual inspection of the gel indicates that between 1 and $2.5 \mathrm{pg}$ of the construct would result in equal band intensities for the sample and the construct PCR products. Densitometric analysis (Fig. 4) of the separated products was carried out with both 5- and 15- $\mu$ l aliquots of the PCR reaction mixture, as well as with 15 $\mu l$ of products obtained after 22 rather than 25 cycles of amplification. The calculated mass value was similar for all three samples $(2.06,2.59$, and $2.81 \mathrm{pg}$, respectively), and showed that the CDNA derived from $1.0 \mu \mathrm{g}$ of astrocyte RNA contained $1.56 \pm 0.24 \mathrm{pg}$ of 284-bp product, equivalent to $15.6 \mathrm{pg}$ of the

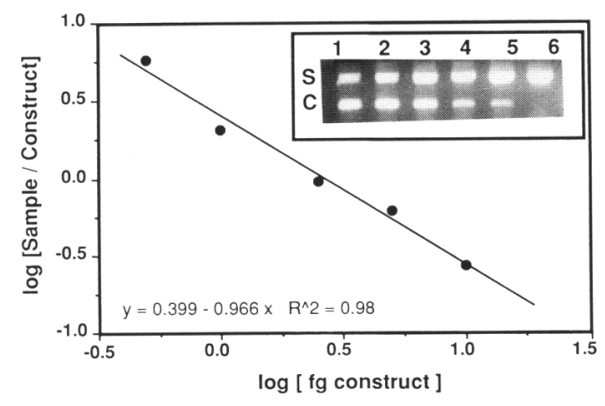

FIGURE 4 Competitive PCR analysis of astrocyte RNA. CDNA was synthesized from $10 \mu \mathrm{g}$ of total cytoplasmic RNA using primer 2 . Equal aliquots of the cDNA were amplified for 25 cycles in the presence of different amounts of the 155-bp deletion fragment, and the products ( $15 \mu \mathrm{l}$ of the $50-\mu \mathrm{l}$ reaction mixture) separated through a $2 \%$ agarose gel (inset). The amount of 155-bp fragment added was (in picograms): $10,5,2.5,1.0,0.5$, and none (lanes 1-6). The locations of the sample (S) and construct (C) PCR product bands are shown. Following electrophoresis, the gel was photographed and the relative band intensities were determined by laser densitometry. In addition to the gel shown, a $5 \mu \mathrm{l}$-aliquot of the PCR mixture was also analyzed, as well as a $15-\mu$ l aliquot taken after 22 rather than 25 cycles. The average of the three determinations is plotted, and the result of linear regression analysis is shown. 2804-nucleotide GFAP mRNA. If we assume a value of $2 \%$ for the percentage of mRNA contained in total cytoplasmic RNA, then GFAP mRNA represented at least $0.078 \%$ of mRNA. However, since we have not yet determined the efficiency of cDNA synthesis, this value remains semiquantitative and may actually underestimate true GFAP mRNA levels.

\section{DISCUSSION}

We have developed a rapid method for producing deletion constructs that can be applied to any gene of known sequence, and have used it for quantitation of rat GFAP mRNA levels in cultured astrocytes. By utilizing PCR amplification as a screening step for the presence of the desired deletion products, lengthy incubations needed for efficient ligation are unnecessary. Presently, approximately 1 full day is required to carry out the three PCR amplifications, the digestion and ligation steps, and a final purification step. It is likely that this procedure can be streamlined further by decreasing the number of cycles, length of cycles, or using more rapid PCR machines. In cases where the specific DNA sequence is not known, test digestions with a panel of restriction enzymes can quickly identify those which cleave three or four times within the gene fragment, and thus be suitable for the synthesis of a deletion construct.

In the synthesis of the GFAP construct we describe, the use of restriction enzyme HaeIII led to the possibility of obtaining homodimeric ligation products whose sizes could not be distinguished from the desired deletion product. For this reason we had to confirm, by using a single primer for amplification or by restriction digestion analysis, that we had obtained the correct product. Since PCR amplification of a complex mixture can potentially yield unexpected products, we suggest that confirmation of construct identity always be carried out, either by the above methods or by direct DNA sequencing.

The calculation of GFAP mRNA levels is based upon the assumption that amplification of the deletion construct is identical to that of the sample template. This does not imply that the amplification efficiencies ( $R$ values) are constant during the entire assay, but that any changes in efficiency that occur to the 
GFAP template also occur to the construct template. Consistent with this, we found that the ratio of GFAP to construct product was similar following 22 and 25 cycles. Since any differences in the amplification efficiencies of the two templates would be expected to result in a large difference in the ratio of GFAP to construct, particularly during the final cycles, our results further suggest that the $R$ values for the two templates were the same during each cycle of the PCR assay. Our calculations show that in primary cultures of rat brain cortical astrocytes GFAP mRNA is expressed at approximately $0.08 \%$ abundance, a value consistent with that expected for a moderate to abundantly expressed mRNA species.

As mentioned above, the efficiency of conversion of GFAP mRNA to cDNA has not been established and hence our estimates of GFAP mRNA levels remain semiquantitative and may underestimate the actual values. Using oligo(dT) to prime the reverse transcriptase (RT) reaction, copy efficiencies of $40-50 \%$ are generally obtained. Since we are using a specific GFAP oligonucleotide as primer, together with a genetically modified RNase $\mathrm{H}^{-}$RT, we expect that the efficiency of conversion should be even greater. For absolute quantification, the use of known amounts of cRNA prepared from the parent template could serve to determine both RT efficiency as well as to define the limits of the quantitative procedure. Alternative methods for achieving absolute measurements have been proposed. $(2,4,5,9,10)$

Although deletion constructs should prove useful for quantitative analysis of mRNA levels, it must be emphasized that multiple parameters need to be established for each individual mRNA species tested. In addition to the ones we have already discussed (RT efficiency and identical $R$ values), it is also necessary to determine the linear range of input mRNA or cDNA that can be used. One possible approach to this has been described previously. ${ }^{(2)}$

In summary, we have presented a rapid method for the synthesis of deletion constructs that can be used for competitive PCR assays. A rat GFAP deletion construct was synthesized and shown to compete with the original template at comparable amplification efficiency. The primers used for these analyses have also proved successful with mouse and human brain RNA samples (unpublished observations). Thus, the rat 155 -bp construct can be used for the determination of GFAP mRNA levels in tissues from other species. As the utilization of competitive PCR becomes more common, the ability to produce internal standards easily and rapidly will prove extremely valuable.

\section{ACKNOWLEDGMENTS}

We thank Liubov Lyandvert for assistance in preparing glial cultures, and Dr. Mary Meeley for helpful discussions. E.G. was supported by a NATO fellowship.

\section{REFERENCES}

1. Gilliland, G., S. Perrin, K. Blanchard, and H.F. Bunn. 1990. Analysis of cytokine mRNA and DNA: Detection and quantitation by competitive polymerase chain reaction. Proc. Natl. Acad. Sci. 87: 27252729.

2. Uberla, K., C. Platzer, T. Diamantstein, and T. Blankenstein. 1991. Generation of competitor DNA fragments for quantitative PCR. PCR Methods Appl. 1: 136-139.

3. Stieger, M., C. Demolliere, L. AhlbornLaake, and J. Mous. 1991. Competitive polymerase chain reaction assay for quantitation of HIV-1 DNA and RNA. J. Virol. Meth. 34: 149-160.

4. Becker-Andre, M. and K. Hahlbrock. 1989. Absolute mRNA quantification using the polymerase chain reaction (PCR). A novel approach by a PCR-aided transcript titration assay (PATTY). Nucleic Acids. Res. 17: $9437-9446$.

5. Wang, A.M., M.V. Doyle, and D.F. Mark. 1989. Quantitation of mRNA by the polymerase chain reaction. Proc. Natl. Acad. Sci. 86: 9717-9721.

6. Feinstein, D.L., M. Durand, and R.J. Milner. 1991. Expression of myosin regulatory light chains in rat brain: Characterization of a novel isoform. Mol. Brain Res. 10: $97-105$.

7. Feinstein, D.L., G.A. Weinmaster, and R.J. Milner. 1992. Isolation of cDNA clones encoding rat glial fibrillary acidic protein: Expression in astrocytes and in Schwann cells. J. Neurosci. Res. 32: 1-14.

8. Sambrook, J., E.F. Fritsch, and T. Maniatis. 1989. Molecular cloning: A laboratory manual, 2nd edition. Cold Spring Harbor Laboratory Press, Cold Spring Harbor, New York.

9. Chelly, J., D. Montarras, C. Pinset, Y. Berwald-Netter, J.-C. Kaplan, and A. Kahn. 1990. Quantitative estimation of minor mRNAs by cDNA polymerase chain reaction: Application to dystrophin mRNA in cultured myogenic and brain cells. Eur. J. Biochem. 187: 691-698.

10. Hoof, T., J.R. Riordan, and B. Tummler. 1991. Quantitation of mRNA by the kinetic polymerase chain reaction assay: $A$ tool for monitoring P-glycoprotein gene expression. Anal. Biochem. 196: 161-169.

Received December 13, 1991; accepted in revised form March 12, 1992. 


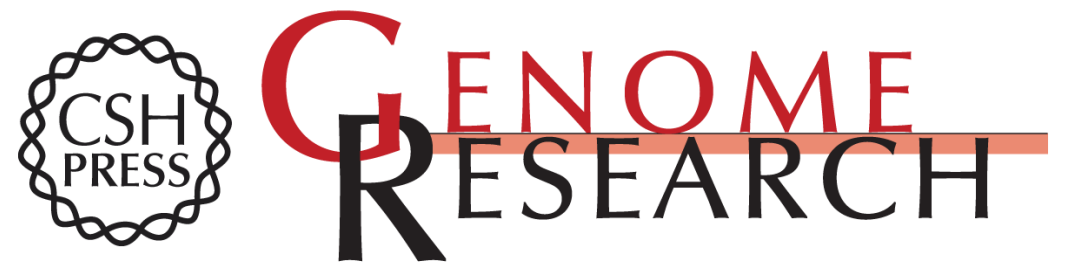

\section{Rapid synthesis of DNA deletion constructs for mRNA quantitation: analysis of astrocyte mRNAs.}

E Galea and D L Feinstein

Genome Res. 1992 2: 66-69

Access the most recent version at doi:10.1101/gr.2.1.66

References This article cites 9 articles, 2 of which can be accessed free at:

http://genome.cshlp.org/content/2/1/66.full.html\#ref-list-1

\section{License}

Email Alerting Receive free email alerts when new articles cite this article - sign up in the box at the Service top right corner of the article or click here.

\section{Affordable, Accurate Sequencing.}

To subscribe to Genome Research go to:

https://genome.cshlp.org/subscriptions 